\title{
Recurrent Plasmablastic Lymphoma
}

National Cancer Institute

\section{Source}

National Cancer Institute. Recurrent Plasmablastic Lymphoma. NCI Thesaurus. Code C157683.

The reemergence of plasmablastic lymphoma after a period of remission. 